\title{
Examining the relationship between completeness of teachers' implementation of the Krachtvoer healthy diet programme and changes in students' dietary intakes
}

\author{
Kathelijne MHH Bessems ${ }^{1, *}$, Patricia van Assema ${ }^{1}$, Rik Crutzen ${ }^{2}$, Theo GWM Paulussen ${ }^{3}$ \\ and Nanne K de Vries ${ }^{1,2}$ \\ 'Department of Health Promotion, NUTRIM School for Nutrition, Toxicology, and Metabolism, Maastricht \\ University Medical Centre, PO Box 616, 6200 MD Maastricht, The Netherlands: ${ }^{2}$ Department of Health \\ Promotion, CAPHRI School for Public Health and Primary Care, Maastricht University Medical Centre, \\ Maastricht, The Netherlands: ${ }^{3} \mathrm{TNO}$ (Netherlands Organization of Applied Scientific Research) \\ Quality of Life, Leiden, The Netherlands
}

Submitted 30 June 2011: Final revision received 30 January 2012: Accepted 17 June 2012: First published online 16 August 2012

\begin{abstract}
Objective: The goal of the current study was to examine if the completeness of programme implementation and the completeness of implementation of specific programme elements of the Dutch school-based healthy diet promotion programme Krachtvoer are related to short- and longer-term changes in students' fruit, sweets and breakfast intakes.

Design: Data on students' dietary intakes were collected 1-4 weeks and 6 months after programme implementation. Teachers filled in a logbook on programme implementation after each lesson. The relationships between changes in students' dietary intakes and completeness of implementation of the programme and of specific programme elements were tested using mixed linear regression analyses. Setting: Thirteen Dutch prevocational schools.

Subjects: Eight hundred and seventy-six of the 1117 participating students and eighteen of the twenty-two participating teachers.

Results: Completeness of programme implementation was positively related to an increase in fruit consumption in the short term. Completeness of implementation of food exposure activities and a practical lesson on advertisements were related to an increase in fruit consumption in the short as well as the longer term. No such relationships were found for sweets and breakfast consumption.

Conclusions: Our results indicate that efforts should be made to help teachers implement the programme as fully as possible.
\end{abstract}

Keywords

School

Nutrition education Implementation
Reviews have found moderate evidence that theory-based healthy diet promotion programmes for children and adolescents in schools can change dietary intakes ${ }^{(1-3)}$. However, as soon as health promotion programmes are used in real-life settings, the most serious threat to their effectiveness is low levels of fidelity of programme implementation, also known as type 3 error $^{(4)}$. Research in a range of settings has shown that various aspects of the implementation of health promotion interventions, such as adherence (implementation as intended by the developers) and completeness (the proportion of the activities proposed by the programme that was actually used), affect programme outcomes ${ }^{(5-7)}$. Derzon et al. re-assessed the outcomes of forty-six effectiveness studies of substance abuse prevention programmes, correcting for implementation and exposure of control groups, and found beneficial programme effects for $46 \%$ of the studies which initially reported no effects ${ }^{(6)}$. Two other studies found that programme outcomes were not only related to overall implementation, but also to the implementation of specific programme elements ${ }^{(8,9)}$. Examining the relationship between the degree of completeness of programme implementation and the variability in programme outcomes can help generate leads for programme improvement and the improvement of implementation strategies.

Krachtvoer is a Dutch school-based healthy diet programme for 12- to 14-year-olds attending the first two years of prevocational education. Programme goals are to increase the consumption of fruit, to decrease the consumption of fats by replacing high-fat snacks and sweets (e.g. chocolates, candy bars) by non-fat or low-fat alternatives (e.g. chewing gum, acid drops) and to stimulate daily consumption of a healthy breakfast ${ }^{(10)}$. The programme consists of eight lessons, including 
lessons with a fixed protocol and optional activities. Some of the lessons are mainly theoretical, for example those with information on national dietary recommendations, while others are mainly practical, for example those including fruit shake preparation or tasting activities. The lessons are intended to be taught during the nutrition lessons by a school teacher of biology (subject which is focused on technical knowledge, e.g. on nutrients) or care (subject which is focused on practical knowledge and skills, e.g. cooking skills).

The programme was originally developed in 2001 and revised in 2007. An effectiveness study of the revised programme revealed both immediate and longer-term (6 months after the end of implementation) increases in students' fruit consumption. As regards snack and sweets intake, students less often consumed sweets from the unfavourable sweets category (e.g. less often chocolates, more often chewing gum or no sweets ${ }^{(11)}$. On the other hand, the trend towards falling breakfast frequencies which is seen among Dutch youngsters between the ages of 12 and 16 years ${ }^{(12)}$ did not slow down as a consequence of the programme.

The goal of the current study was to examine the relationship between changes in students' dietary intakes and the level of completeness of implementation of the full programme and of specific programme elements. We used an outcome measure of fruit consumption and sweets consumption for which short- and longer-term effects had been found in the effectiveness study ${ }^{(11)}$. Although the effectiveness study found no effects on breakfast frequency (i.e. breakfast frequency decreased in the intervention and in the control group), we included this measure to examine whether the lack of effect could be explained by a type 3 error. Specific research questions were:

1. Can the favourable changes in fruit and sweets consumption found in the effectiveness study be related to the completeness of programme implementation and to the completeness of implementation of specific programme elements?

2. Can the unfavourable changes in breakfast consumption found in the effectiveness study be related to suboptimal programme implementation and incomplete implementation of specific programme elements?

\section{Content of the programme}

The main programme elements are one lesson to make students enthusiastic about the programme (lesson 1), three lessons for raising awareness (lessons 2 to the first part of lesson 4), one practical food exposure activity (i.e. taste testing, fruit tasting or preparing a fruit shake: lesson 5), one lesson on the influence of advertisements (lesson 6) and two lessons in which students formulate, implement and evaluate a personal action plan (lessons 7 and 8). Before the start of the programme teachers can choose the optional lesson on nutrients (lesson 0). Additional optional programme elements within lesson 4 (second part) and lesson 7 (first part) are participating in a nationwide recipe contest (as homework), reading and discussing the Krachtvoer magazine, knowledge tests on the programme website, and additional food exposure activities as proposed in lesson 5.

The programme builds on the three phases of selfmanagement theory ${ }^{(13)}$, successively aiming at raising awareness of personal dietary intakes, proposing solutions in order to meet the Dutch dietary guidelines and setting personal goals for dietary improvement ${ }^{(10,14)}$. A programme overview is presented in Box 1. A more extensive programme description is published elsewhere ${ }^{(10)}$.

\section{Methods}

\section{Study design, sample and data collection}

We included students and teachers from the intervention condition of the effectiveness study, i.e. students who were taught the Krachtvoer programme and the teachers who implemented the programme ${ }^{(11)}$. Respondents from the control condition were not included since they were not exposed to any element of the programme, but received another nutrition education programme.

Data were collected from thirteen schools, fifty-three classes and 1117 students. Student questionnaires were filled in as a classroom activity at baseline (T0; $1-4$ weeks before the lessons), at post-test (T1; $1-4$ weeks after the lessons) and at the follow-up test (T2; 6 months after the lessons). Students who objected to participation were allowed to do another task during the lesson. The study was exempt from ethical review according to prevailing Dutch standards because there was no risk for participants and participation was voluntary ${ }^{(15)}$. Completeness of implementation was assessed using teacher logbooks. All twenty-two teachers who implemented Krachtvoer were asked to fill in the logbook after each lesson.

\section{Measures}

The student questionnaire assessed background variables, i.e. gender, country of birth of both parents as an indicator of ethnicity (non-Dutch if one or both parents had been born abroad ${ }^{(16)}$ ) and postal code as an indicator of socioeconomic position (SEP) ${ }^{(17)}$. Teachers provided data on school-related variables, including the school year of their class (first or second year) and the educational sub-track within the Dutch prevocational education system (lower (sub-track 2) or higher (sub-tracks 3 and 4)).

Fruit consumption items were derived from a validated fruit and vegetable $\mathrm{FFQ}^{(18)}$, and included an item on the number of days a week on which fruit was usually consumed and an item on the number of servings of fruit consumed on these days. Examples of one serving of fruit (e.g. one apple, one bowl of strawberries) and half a serving of fruit (e.g. one mandarin) were added to the question. Frequency and quantity scores were multiplied 
Box 1 The Krachtvoer programme

Lessons

The programme covers eight lessons and one optional pre-programme lesson on nutrients. Some slots in the lessons 4, 5, 7 and 8 can be filled by six optional activities (of which at least two should be used).

- Before the start of the programme:

Lesson 0: Nutrients (optional element). Students learn about nutrients (e.g. saturated fats, carbohydrates), their functions in the human body and food products containing these nutrients

- Phase 1. Students are made aware of their own dietary intake and deviations from the Dutch dietary guidelines.

$\circ$ Lesson 1: Nutrition, foods and health (fixed element). Students' knowledge on fruit, breakfast and high-fat snacks is tested in a quiz. Students receive a lunchbox with a flyer and three healthy food items representing the three topics.

$\circ$ Lesson 2: Fruit and fruit juices (fixed element). Students learn to read fruit juice labels. Knowledge about the differences between fruit juices and other juices is tested with a fruit juice test. They are made aware of their own fruit or fruit juice consumption, and become familiar with national recommendations.

$\circ$ Lesson 3: Breakfast and snacking (fixed element). Students are made aware of their own breakfast habits and high-fat snack consumption. The disc of five and an overview of low- and high-fat snacks are discussed and compared with their own breakfast and snack intakes.

- Phase 2. Students specify reasons for deviations and are encouraged to propose solutions.

$\circ$ Lesson 4 (part 1): Barriers to healthy eating (fixed element). Students answer questions on personal reasons for (not) meeting the dietary recommendations on fruit, breakfast and snack intakes, and give each other tips on healthy eating. Students receive a take-home bag with healthy products, a newsletter with tips and recipes, and a notepad designed to involve their parents.

$\circ$ Lesson 4 (part 2) and lesson 7 (part 1) (optional element).

- National recipe contest. Students participate in a national recipe contest.

- Magazine. Students work with a magazine offering information, tests, puzzles, a horoscope, role model stories and healthy recipes.

- Website. Students visit the Krachtvoer website to read information, do a snack test (i.e. distinguishing between high- and low-fat snacks) and a knowledge test (e.g. practical and theoretical knowledge about fruit, breakfast and snacks), and send e-cards.

$\circ$ Lesson 5. Food exposure (teachers can choose one or more elements).

- Taste testing. Students judge products by tasting, smelling and looking at (unfamiliar) fruit, breakfast products and favourable snacks.

- Fruit tasting. Students bring fruits from home to school and taste them together.

- Preparing a fruit shake. Students prepare a healthy tasty fruit shake

$\circ$ Lesson 6. Advertisements ( fixed element). Advertising tricks are discussed and are applied in an advertising poster produced by the students.

- Phase 3. Students implement and evaluate an action plan.

$\circ$ Lesson 7 (part 2): Personal action plans (fixed element). Students use a program on the website to generate a personal action plan (what, when, where) to improve their fruit, breakfast or snack intake during the next week.

$\circ$ Lesson 8: Evaluation of personal plans (fixed element). In-class evaluation of the action plans, followed by an optional activity.

and divided by seven to obtain the average fruit consumption per day. One item was used to measure the usual consumption of sweets. In line with the programme and the dietary guidelines provided by the Netherlands Nutrition Centre ${ }^{(19)}$, a distinction was made between unfavourable types of sweets (e.g. chocolates, candy bars) and more favourable types (e.g. acid drops, chewing gum). Frequency items were formulated (e.g. 'Which category of sweets do you usually eat?', with options 'I do not eat sweets', 'I usually eat... (followed by examples of favourable products)', 'I usually eat... (followed by examples of unfavourable products)' and 'I eat sweets from both categories equally'). Breakfast consumption was measured with one FFQ item about the number of days per week on which breakfast was usually consumed.

Completeness of implementation was measured by asking teachers to indicate which programme elements (lessons and optional activities) they had implemented. For each of thirteen programme elements as proposed in Box 1 (except for the optional recipe contest which was a homework assignment), teachers could tick off the activities they had implemented on a list of all proposed activities. A score for completeness of element implementation (range 0-1) was calculated by dividing the number of implemented activities by the number of proposed activities within that programme element. A score for completeness of programme implementation (range 0-13) was calculated as the sum of the scores for the activities of each programme element.

\section{Statistical analysis}

Student and teacher data were matched on demographics, class and school. Change scores for the continuous outcomes of fruit and breakfast intake were calculated by 
subtracting baseline scores from the scores at the two posttests. The four answering categories of sweets consumption were dichotomized into two new categories: favourable consumption ('no sweets' and 'favourable products') $v$. unfavourable consumption ('unfavourable products' and 'both favourable and unfavourable products'). Descriptive statistics were used to describe the background characteristics of participating students and teachers, and the percentages of students who had changed their fruit, sweets and breakfast intakes at the two post-tests. Mixed linear regression analyses were carried out using the statistical software packages PASW Statistics 17 for continuous outcomes and MLwiN version $2 \cdot 02$ for binary outcomes. We tested for selective student drop-out (due to missing post-test data or implementation data) with mixed logistic regressions using MLwiN, with drop-out at any moment as the outcome variable (inclusion $=1$, dropout $=0$ ), and with student background variables (gender, ethnicity, SEP, school year and educational sub-track) and baseline dietary intake variables (fruit, sweets, breakfast) as fixed factors, and with a random intercept of the class the student was in. Pearson's correlations were calculated to check if implementation scores for the thirteen programme elements were strongly interrelated. Based on high Pearson's correlations $(>0.75)$ and the content of programme elements, two sum scores were calculated, one for lessons 1 to 4 (creating awareness; range 0-4) and one for lessons 7 and 8 (personal plans; range 0-2). Since there was little variation between teachers implementing the three practical activities, we calculated one sum score for the taste testing, fruit tasting and fruit shake preparation activities (range 0-3).

The relationships between changes in fruit and breakfast consumption and completeness of programme and element implementation were tested by mixed linear regression analyses for the individual post-tests, with change scores of fruit or breakfast as outcome variables, and gender, ethnicity, SEP, year (first or second) and sub-track as fixed factors. The first analysis included completeness of programme implementation as a factor, while the second analysis included completeness of the implementation of the individual elements, including lesson 0 (range $0-1$ ), the lessons on awareness (range $0-4$ ), the practical activities (range 0-3), the advertisement lesson (range 0-1), the tests on the website (range $0-1$ ), the magazine lesson (range $0-1$ ) and the lessons on action plans (range 0-2). Comparable mixed logistic regression analyses were conducted for the dichotomous outcomes on sweets consumption, correcting for baseline intake.

\section{Results}

\section{Response rates and participant characteristics}

Eighteen of the twenty-two participating teachers filled in the teacher logbook after each lesson. They had implemented the lessons in forty-five of the fifty-three participating classes, in lessons on biology ( $n$ 6), care ( $n$ 6) or a combination both subjects ( $n$ 6), over an average period of $59(\mathrm{SD} 26 \cdot 5) \mathrm{d}$. Four teachers did not fill in the teacher logbook, which meant that 154 students in their classes were excluded from the study. Additionally, sixty-six students had to be excluded at the first post-test, and eighty-seven were excluded at the second post-test, as they had been absent from the lesson in which the questionnaire was completed or had incomplete background characteristics, making it impossible to link the data of separate measurements. Analyses at the first posttest included a total of 897 students, while those at the second post-test included 876 students. Students who dropped out of the study were significantly more often second-year students $(\mathrm{OR}=1 \cdot 67,95 \%$ CI $1 \cdot 13,2 \cdot 47$; $P<0 \cdot 01)$ and had consumed breakfast less frequently before programme implementation $(\mathrm{OR}=0 \cdot 91,95 \% \mathrm{CI}$ 0.83, 0.98; $P<0 \cdot 05)$.

Half of the participating students were male. The majority of the students were in the second year $(60 \cdot 0 \%)$, attended the higher educational sub-track $(85 \cdot 1 \%)$ and were of Dutch ethnicity (79.8\%). The mean SEP score was comparable to the average Dutch SEP score (mean for participants $=-0.05$; Dutch mean $=0.00$ (scale 4 to -4 ; low to high)). The students included in the study had less than $5.0 \%$ missing values on all items, except for sweets consumption (missing values $\mathrm{T} 1=8 \cdot 0 \%$; missing values $\mathrm{T} 2=10 \cdot 2 \%)$.

\section{Changes in fruit, sweets and breakfast consumption}

Mean fruit consumption at baseline was 0.97 (SD 0.78) servings/d. A total of $58.6 \%$ of the students usually consumed sweets from the unfavourable category. At baseline, the mean number of days per week on which breakfast was consumed was $6 \cdot 31$ (SD 1·61).

Table 1 shows that mean fruit intake increased in the short term $(+0 \cdot 14$ pieces/d) as well as in the longer term $(+0.06$ pieces $/ \mathrm{d})$. At the first and second post-test, 16.4\% and $18.5 \%$ of the students, respectively, had shifted their usual sweets consumption from the unfavourable category towards the favourable category. The mean number of days on which breakfast was consumed had decreased by $0 \cdot 20$ and $0 \cdot 17 \mathrm{~d} /$ week at the first and second post-tests, respectively.

\section{Completeness of implementation of the programme and of specific programme elements}

The mean score for completeness of programme implementation was $8 \cdot 0(\mathrm{SD} 1 \cdot 9$; range $4 \cdot 8-11 \cdot 0)$. Table 2 shows that the lowest score for completeness of implementation was found for the action plan lesson (mean $=0 \cdot 47$ ), while the fruit shake preparation activity was most fully implemented (mean $=0 \cdot 90$ ). The first fixed lessons were implemented more completely than the later lessons. 
Table 1 Changes in fruit, sweets and breakfast consumption among Dutch students $(n 876)$ in thirteen prevocational schools participating in the Krachtvoer healthy diet promotion programme

\begin{tabular}{|c|c|c|c|c|c|c|c|c|c|c|}
\hline & \multicolumn{5}{|c|}{ First post-test compared with baseline } & \multicolumn{5}{|c|}{ Second post-test compared with baseline } \\
\hline & \multicolumn{2}{|c|}{ Change score } & \multirow{2}{*}{$\begin{array}{c}\% \text { of } \\
\text { favourable } \\
\text { change } \\
\text { scores }\end{array}$} & \multirow{2}{*}{$\begin{array}{c}\% \text { of } \\
\text { unchanged } \\
\text { scores }\end{array}$} & \multirow{2}{*}{$\begin{array}{c}\% \text { of } \\
\text { unfavourable } \\
\text { change } \\
\text { scores }\end{array}$} & \multicolumn{2}{|c|}{ Change score } & \multirow{2}{*}{$\begin{array}{c}\% \text { of } \\
\text { favourable } \\
\text { change } \\
\text { scores }\end{array}$} & \multirow{2}{*}{$\begin{array}{c}\% \text { of } \\
\text { unchanged } \\
\text { scores }\end{array}$} & \multirow{2}{*}{$\begin{array}{c}\% \text { of } \\
\text { unfavourable } \\
\text { change } \\
\text { scores }\end{array}$} \\
\hline & Mean & SD & & & & Mean & SD & & & \\
\hline $\begin{array}{l}\text { Fruit frequency } \\
\text { (servings/d) }\end{array}$ & $0 \cdot 14$ & $0 \cdot 78$ & $45 \cdot 4$ & $16 \cdot 9$ & $37 \cdot 7$ & 0.06 & $0 \cdot 78$ & $44 \cdot 7$ & $16 \cdot 5$ & $38 \cdot 8$ \\
\hline $\begin{array}{l}\text { Usual consumption } \\
\text { of sweets }\end{array}$ & n.a. & n.a. & $16 \cdot 4$ & $69 \cdot 3$ & $14 \cdot 3$ & n.a. & n.a. & $18 \cdot 5$ & $67 \cdot 3$ & $14 \cdot 2$ \\
\hline $\begin{array}{l}\text { Breakfast frequency } \\
\text { (d/week) }\end{array}$ & $-0 \cdot 20$ & $1 \cdot 57$ & $9 \cdot 2$ & $66 \cdot 9$ & $23 \cdot 9$ & $-0 \cdot 17$ & $1 \cdot 72$ & $12 \cdot 2$ & $66 \cdot 9$ & $20 \cdot 9$ \\
\hline
\end{tabular}

n.a., no mean change score could be calculated for dichotomous outcome measures.

Table 2 Number of teachers who completed the lesson or activity and completeness of implementation of programme elements, assessed in terms of mean score, standard deviation and range, among Dutch teachers $(n 18)$ in thirteen prevocational schools participating in the Krachtvoer healthy diet promotion programme

\begin{tabular}{|c|c|c|c|c|c|}
\hline & & \multirow{2}{*}{$\begin{array}{c}\text { No. of teachers who implemented } \\
\text { the lesson or activity }\end{array}$} & \multicolumn{3}{|c|}{ Completeness of implementation } \\
\hline & & & Mean score & SD & Range \\
\hline Lesson & Fixed lesson & & & & \\
\hline 1 & Nutrition, foods and health & 18 & $1 \cdot 00+$ & 0.00 & \\
\hline 2 & Fruit and fruit juices & 18 & $0 \cdot 78$ & 0.21 & $0.29-1.00$ \\
\hline 3 & Breakfast and snacking & 18 & $0 \cdot 64$ & 0.25 & $0.08-1 \cdot 00$ \\
\hline 4 & Part 1: Barriers to healthy eating & 15 & $0 \cdot 75$ & 0.27 & $0 \cdot 20-1 \cdot 00$ \\
\hline 6 & Advertisements & 15 & 0.56 & 0.25 & $0 \cdot 20-1 \cdot 00$ \\
\hline 7 & Part 2: Personal action plans & 15 & $0 \cdot 47$ & 0.30 & $0 \cdot 14-1.00$ \\
\hline \multirow[t]{2}{*}{8} & Evaluation of personal plans & 11 & $1 \cdot 00+$ & 0.00 & \\
\hline & Optional activities & & & & \\
\hline 0 & Lesson on nutrients & 15 & $0 \cdot 77$ & 0.20 & $0.50-1.00$ \\
\hline 5 & Taste testing & 17 & $0 \cdot 88$ & 0.22 & $0.50-1.00$ \\
\hline 5 & Fruit tasting & 4 & $1 \cdot 00+$ & 0.00 & \\
\hline 5 & Preparing a fruit shake & 5 & 0.90 & 0.22 & $0.50-1.00$ \\
\hline $4 / 7$ & Tests on website & 13 & $1 \cdot 00 t$ & 0.00 & \\
\hline \multirow[t]{2}{*}{$4 / 7$} & Magazine & 14 & $1 \cdot 00 t$ & 0.00 & \\
\hline & Total programme completeness score & & $8 \cdot 00$ & 1.90 & $4 \cdot 79-11 \cdot 00$ \\
\hline
\end{tabular}

tTwo lessons and three optional activities consisted of one activity only.

\section{Changes in dietary intakes in relation to completeness of implementation of the programme and of specific programme elements}

Table 3 shows the relationships between the scores for completeness of implementation of the programme and specific elements and the short-term and longer-term changes in students' fruit, sweets and breakfast consumption. The score for completeness of programme implementation was significantly related to an increase in fruit consumption in the short term. The scores for completeness of implementation of the practical activities and the advertisement lesson were significantly related to an increase in fruit consumption in the short and longer term. No other significant relationships were found.

\section{Discussion}

The first aim of the present study was to investigate whether favourable changes in fruit and sweets consumption that were found in an effectiveness study could be related to the completeness of the implementation of the Krachtvoer programme and the completeness of implementation of specific programme elements. The second aim was to examine whether unfavourable changes found in breakfast consumption could be related to the incompleteness of the programme implementation and the incompleteness of implementation of specific programme elements.

We found that the completeness of implementation of the programme was related to short-term, but not longer-term increases in fruit consumption. A possible explanation is that Krachtvoer, and the instrument used to measure its completeness of programme implementation, included elements not only addressing fruit consumption, but also snack and breakfast consumption. The sensitivity of our measure may have been especially problematic in the long term when the programme effect had decreased. Furthermore, completeness of implementation of the food exposure activities and the advertisement activity was related to both short- and longer-term changes in fruit consumption, 
implying that these elements made a unique contribution towards changes in fruit consumption. Increased fruit consumption was not only related to programme elements addressing fruit and fruit juices (i.e. taste testing, fruit tasting and preparation of a fruit shake), but also to a programme element which focused on environmental influences on food consumption in general (advertisement activity, applying advertisement tricks). These were all very practical activities, which were implemented with high levels of completeness by the teachers, and were appreciated better by the students than all other elements ${ }^{(10)}$. This importance of practical activities is in agreement with the findings of a qualitative study that was held among students during the process of developing the programme, and that indicated the importance of tasting and recipe preparation activities (e.g. preparing a fruit shake), as well as other activities in which students were allowed 'to doing things themselves $^{,(20)}$. The importance of appreciation is in agreement with studies that also found appreciation to be related to changes in dietary intakes ${ }^{(21,22)}$. The key element of Krachtvoer seems to be that it uses practical and highly appreciated methods, which are effectively implemented by teachers. It is worth exploring if appreciation mediates the relationship between programme outcomes and the completeness of implementation of certain activities.

We found no relationships between sweets consumption and the completeness of implementation of the programme or specific elements, possibly because our outcome measure for sweets consumption lacked sensitivity. We recommend studying this relationship using a more sensitive item combining type of sweets and frequency of consumption.

Further, our findings indicate that the lack of effect on breakfast intake found in the effectiveness study ${ }^{(11)}$ was not attributable to incomplete implementation. This finding stresses the conclusion of the effectiveness study, that our school-based educational intervention was unable to change breakfast consumption.

The current study had some limitations as well as some strengths. Overall, the programme elements were implemented quite well (with completeness scores for specific programme elements ranging from 0.47 to 0.90 ), indicating that there was limited variation in the completeness of implementation scores between teachers. This made it more difficult to answer our research questions. Using a sensitive score for completeness of implementation (counting the number of activities that were implemented in each programme element) enabled us to include the separate programme elements in our analyses that were implemented by all teachers (i.e. lessons 1-3). Still, if our sample had shown more variation regarding implementation scores of these lessons, a relationship between the completeness of implementation of these lessons and the changes in dietary patterns might have been revealed as well. A strong point of our study was that we assessed the completeness scores for individual programme elements, which helped us distinguish the relative importance of individual programme 
elements. Still, the implementation of these specific elements may have been related to other aspects which were not measured, such as teachers' enthusiasm and respect for students' opinions ${ }^{(23)}$ or students' engagement ${ }^{(24)}$, or may have been a result of multiple testing. However, the findings on the importance of full implementation of practical programme elements are consistent over time and in line with the findings of an earlier qualitative study ${ }^{(20)}$, and are therefore considered to be plausible. Another limitation was the use of logbooks to measure programme implementation. Although observational methods have been recommended to measure implementation ${ }^{(7)}$, these are more time-consuming and hence were infeasible within the context of the current study. Completeness is only one element of the fidelity of programme implementation and the present study did not asses programme adherence and quality, which have been shown to be related to outcomes of interventions to prevent drug abuse ${ }^{(23)}$. We therefore recommend that future studies consider including assessment of completeness, quality, adherence, responsiveness and differentiation ${ }^{(25,26)}$. However, the time investment required for this may be prohibitive for large research populations. Finally, we did not include control schools in the current study since these were irrelevant for the present research questions. Therefore, relative changes in the intervention schools as compared with controls as were obtained in the effectiveness study have not been considered here.

\section{Conclusions}

Our study has indicated the importance of stimulating teachers to implement the Krachtvoer programme to a high level of completeness, with a strong emphasis on the practical elements. To our knowledge, we are among the first to try and quantify the contributions of the implementation of particular programme elements to outcomes on dietary patterns. Although including the completeness of implementation of programme elements in a randomized controlled trial is a challenge, we would still strongly recommend this for future studies. It can help distinguish a minimum required level of completeness of implementation, as well as distinguish which programme elements are essential, thus providing directions for programme implementation strategies. Further studies should explore appreciation as a mediator of the relationship between the completeness of implementation of various types of activities and programme outcomes.

\section{Acknowledgements}

This work was supported by the Netherlands Organisation for Health Research and Development (ZonMw), grant number 63200011. The authors declare that there are no conflicts of interest. All authors contributed to the design of the study. K.M.H.H.B. and R.C. performed statistical analyses. K.M.H.H.B. and P.v.A. prepared a draft of the manuscript. All authors contributed to reviewing and improving the manuscript in terms of content and approved the final manuscript.

\section{References}

1. Ammerman AS, Lindquist CH, Lohr KN et al. (2002) The efficacy of behavioral interventions to modify dietary fat and fruit and vegetable intake: a review of the evidence. Prev Med 35, 25-41.

2. Knai C, Pomerleau J, Lock K et al. (2006) Getting children to eat more fruit and vegetables: a systematic review. Prev Med 42, 85-95.

3. Van Cauwenberghe E, Maes L, Spittaels H et al. (2010) Effectiveness of school-based interventions in Europe to promote healthy nutrition in children and adolescents: systematic review of published and 'grey' literature. BrJ Nutr 103, 781-797.

4. Dobson D \& Cook TJ (1980) Avoiding type 3 errors in program evaluation: results from a field experiment. Eval Program Plann 3, 269-276.

5. Wilson KD \& Kurz RS (2008) Bridging implementation and institutionalization within organizations: proposed employment of continuous quality improvement to further dissemination. J Public Health Manag Pract 14, 109-116.

6. Derzon JH, Sale E, Springer JF et al. (2005) Estimating intervention effectiveness: synthetic projection of field evaluation results. J Prim Prev 26, 321-343.

7. Durlak JA \& DuPre EP (2008) Implementation matters: a review of research on the influence of implementation on program outcomes and the factors affecting implementation. Am J Community Psychol 41, 327-350.

8. Stevens V, Van Oost P \& De Bourdeaudhuij I (2001) Implementation process of the Flemish antibullying intervention and relation with program effectiveness. J Sch Psychol 39, 303-317.

9. Telzrow CF, McNamara K \& Hollinger CL (2000) Fidelity of problem-solving implementation and relationship to student performance. Sch Psychol Rev 29, 443-461.

10. Bessems KMHH, Van Assema P, Martens MK et al. (2011) Appreciation and implementation of the Krachtvoer healthy diet promotion programme for 12- to 14-year-old students of prevocational schools. BMC Public Health 11, 909 .

11. Bessems KMHH (2011) The dissemination of the healthy diet programme Krachtvoer for Dutch prevocational schools. PhD Thesis, Maastricht University.

12. Raaijmakers LGM, Bessems KMHH, Kremers SPJ et al. (2009) Breakfast consumption among children and adolescents in the Netherlands. Eur J Public Health 20, 318-324.

13. Boekaerts M, Rintrich PR \& Zeider M (2000) Handbook of Self Regulation. San Diego, CA: Academic Press.

14. Martens M, Van Assema P, Paulussen T et al. (2006) Krachtvoer: process evaluation of a Dutch programme for lower vocational schools to promote healthful diet. Health Educ Res 21, 695-704

15. Central Committee on Research Involving Human Subjects (2003) Website on guidelines for involving human subjects in Dutch scientific research. http://www.ccmo-online.nl (accessed April 2011).

16. Keij I (2000) Standaarddefinitie allochtonen (Standard Definition of Ethnic Minorities). Heerlen: CBS.

17. Sociaal Cultureel Planbureau (2006) Statusscores postcodegebieden (Status Scores Postal Code Areas). Den Haag: Sociaal Cultureel Planbureau. 
18. Van Assema P, Brug J, Ronda G et al. (2002) A short Dutch questionnaire to measure fruit and vegetable intake: relative validity among adults and adolescents. Nutr Health 16, 85-106.

19. Voedingscentrum (2006) Assortimentsmeter. Den Haag: Voedingscentrum.

20. Martens M, Wind M, Van Assema P et al. (2002) De (on)mogelijkheden van voedingsvoorlichting aan twaalf- tot veertienjarige jongeren Nederlands Tijdschrift voor Dietisten (The (im)possibilities of nutrition education to twelve to fourteen year old adolescents). Dutch J Diet 57, 71-77.

21. Tak NI, Te Velde SJ \& Brug J (2009) Long-term effects of the Dutch Schoolgruiten Project - promoting fruit and vegetable consumption among primary-school children. Public Health Nutr 12, 1213-1223.

22. Wind M, Bjelland M, Perez-Rodrigo C et al. (2008) Appreciation and implementation of a school-based intervention are associated with changes in fruit and vegetable intake in 10- to 13-year old schoolchildren - the Pro Children study. Health Educ Res 23, 997-1007.

23. Dusenbury L, Brannigan R, Falco M et al. (2003) A review of research on fidelity of implementation: implications for drug abuse prevention in school settings. Health Educ Res 18, 237-256.

24. Ringwalt C, Pankratz M, Gottfredson N et al. (2000) The effects of students' curriculum engagement, attitudes toward their teachers, and perception of their teachers' skills on school-based prevention curriculum outcomes. J Drug Educ 39, 223-237.

25. Proctor E, Silmere H, Raghavan R et al. (2011) Outcomes for implementation research: conceptual distinctions, measurement challenges, and research agenda. Adm Pol Ment Health 38, 65-76.

26. Carroll C, Patterson M, Wood S et al. (2007) A conceptual framework for implementation fidelity. Implement Sci 2,40 . 